\title{
Carcinoma de glándulas sebáceas en párpado superior
}

\section{Sebaceous gland carcinoma in upper eyelid}

\author{
René H. Parada-Vásquez ${ }^{1 *}$, Juan P. Medina-López ${ }^{2}$ y Rogerio Martins-Baia ${ }^{3}$
}

${ }^{1}$ Fellowship de segmento anterior; ${ }^{2}$ Residente de $3^{\text {er }}$ año de Oftalmología; ${ }^{3} J e f e$ de Servicio de Oculoplástica. Instituto de la Visión, Hospital La Carlota, Montemorelos, Nuevo León, México

Paciente varón de 68 años de edad que presenta en la órbita izquierda una lesión ulcerada, con bordes irregulares y pérdida de la arquitectura del tercio medio a interno del párpado superior (Fig. 1), observándose madarosis en el área del borde libre palpebral de dicha lesión (Fig. 2), córnea con edema sectorial superior, con

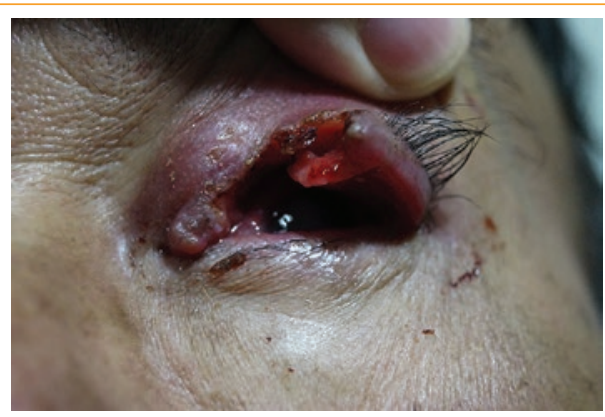

Figura 1. Vista de frente, se aprecia lesión ulcerada con bordes irregulares y pérdida de la arquitectura palpebral superior.

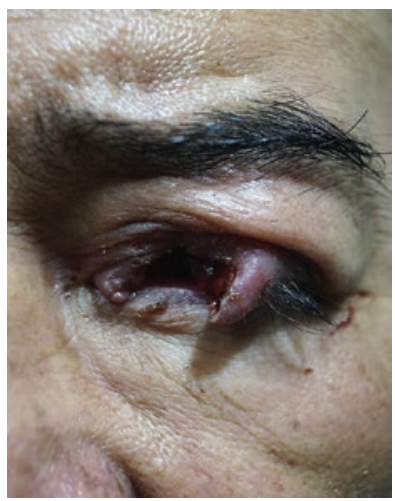

Figura 2. Vista superior, donde se observa la pérdida del tercio medio a interno del párpado superior y área de madarosis. tinción puntiforme. El resto de la exploración del polo posterior resultó sin alteraciones. Tiene el antecedente de haber recibido radioterapia hace 3 años, por tumoración no especificada en el párpado superior izquierdo. Se realiza biopsia incisional, reportando una neoplasia compuesta por células epitelioides de acentuado pleomorfismo, dando como diagnóstico carcinoma de glándulas sebáceas diferenciado, invasivo, ulcerado y primario de párpado izquierdo ${ }^{1}$.

\section{Responsabilidades éticas}

Protección de personas y animales. Los autores declaran que para esta investigación no se han realizado experimentos en seres humanos ni en animales.

Confidencialidad de los datos. Los autores declaran que ha seguido los protocolos de su centro de trabajo sobre la publicación de datos de pacientes.

Derecho a la privacidad y consentimiento informado. Los autores han obtenido el consentimiento informado de los pacientes y/o sujetos referidos en el artículo. Este documento obra en poder del autor de correspondencia.

\section{Financiamiento}

Los autores no recibieron patrocinio para llevar a cabo este artículo.

\section{Conflicto de intereses}

Los autores declaran no tener ningún conflicto de intereses.

\section{Bibliografía}

1. Kanski JJ, Bowling B. Kanski Oftalmología clínica. Séptima edición España: Elsevier; 2012. p. 20-1.

\section{Correspondencia:}

*René Hernán Parada-Vásquez E-mail: rene_hernan@ @hotmail.com DOI: 10.1016/j.mexoft.2016.08.001
Disponible en internet: 02-07-2018 Rev Mex Oftalmol. 2018;92(4):220-220

www.rmo.com.mx CC BY-NC-ND (http://creativecommons.org/licenses/by-nc-nd/4.0/). 